\title{
General election effect on the network topology of Pakistan's stock market: network-based study of a political event
}

\author{
Bilal Ahmed Memon ${ }^{1 *} \mathbb{D}$, Hongxing Yao ${ }^{1}$ and Rabia Tahir ${ }^{2}$
}

\footnotetext{
* Correspondence: Bmemon27@ gmail.com; bmemon1@yahoo.com ${ }^{1}$ School of Finance and Economics, Jiangsu University, 01 Xuefu Road, Zhenjiang 212013, Jiangsu, China Full list of author information is available at the end of the article
}

\begin{abstract}
To examine the interdependency and evolution of Pakistan's stock market, we consider the cross-correlation coefficients of daily stock returns belonging to the blue chip Karachi stock exchange (KSE-100) index. Using the minimum spanning tree network-based method, we extend the financial network literature by examining the topological properties of the network and generating six minimum spanning tree networks around three general elections in Pakistan. Our results reveal a star-like structure after the general elections of 2018 and before those in 2008, and a tree-like structure otherwise. We also highlight key nodes, the presence of different clusters, and compare the differences between the three elections. Additionally, the sectorial centrality measures reveal economic expansion in three industrial sectors-cement, oil and gas, and fertilizers. Moreover, a strong overall intermediary role of the fertilizer sector is observed. The results indicate a structural change in the stock market network due to general elections. Consequently, through this analysis, policy makers can focus on monitoring key nodes around general elections to estimate stock market stability, while local and international investors can form optimal diversification strategies.
\end{abstract}

Keywords: Minimum spanning tree, Centrality measures, General elections, Emerging market, Pakistan, Stock market network

\section{Introduction}

Political risk is a key factor affecting the performance of a country's financial market. There are many ways political risk can take place, such as a change in legislation, general elections, or a political regime shift. According to (Pantzalis et al. 2000), positive stock returns are expected after the resolution of political uncertainty. Additionally, political events capture investor attention due to the possible revision of their investment strategies, depending on the outcome of the event (Pástor and Veronesi 2013). Previous research proposes various methods to study the impact of elections on stock markets [e.g., GARCH and Cumulative abnormal volatility (CAV) (Białkowski et al. 2008), Support vector regression (Chiu et al. 2012), Cumulative average abnormal returns (CAAR) and Abnormal returns AR (Oehler et al. 2013; Savita and Ramesh 2015), Regression analysis (Abidin et al. 2010; Liew and Rowland 2016) Granger

(c) The Author(s). 2020 Open Access This article is distributed under the terms of the Creative Commons Attribution 4.0 International License (http://creativecommons.org/licenses/by/4.0/), which permits unrestricted use, distribution, and reproduction in any medium, provided you give appropriate credit to the original author(s) and the source, provide a link to the Creative Commons license, and indicate if changes were made. 
cointegration and Johansen test (Goodell et al. 2015), and DCC bivariate GARCH (Sultonov and Jehan 2018)].

We extend the financial network literature by studying the impact of general elections on the network topology of Pakistan's stock market. Network-based methods are widely applied by researchers to study interdependency and the evolution of stock markets, such as minimum spanning tree (MST) (Mantegna 1999; Onnela et al. 2003b; Zhao et al. 2018; Yao and Memon 2019), threshold networks (CT) (Boginski et al. 2005; Lee and Nobi 2018), planar maximally filtered graphs (PMFG) (Tumminello et al. 2005; Yan et al. 2015; Musmeci et al. 2016), wavelet (Wang et al. 2017), and multiple criteria decision making (MCDM) (Kou et al. 2014). We have chosen MST, a main network mapping methodology extensively used to analyze various financial crisis (Wiliński et al. 2013; Majapa and Gossel 2016; Coletti and Murgia 2016; Xia et al. 2018; Memon and Yao 2019; Kou et al. 2019), currency crisis (Jang et al. 2011; Sultornsanee et al. 2013), sovereign debt crisis events (Dias 2012), as well as macroeconomic phases (Zhang et al. 2011). Therefore, this paper examines the interdependency and evolution of Pakistan's stock market by using MST before and after the general elections of 2018, 2013, and 2008.

In the summary, our study has made two contributions. First, we fill a research gap by examining the stock market's structural change and topological evolution around a political event: general elections. Unlike previous studies, that apply network-based methods to examine crisis related events of stock markets (Onnela et al. 2003a; Yang et al. 2014; Radhakrishnan et al. 2016), assesses structural change of stock market around other political event (Yao and Memon 2019), and does not take into consideration structural change and topological evolution particularly across general elections. Second, we apply MST around the three general elections in an emerging stock market instead of a developed stock market. Thus, understanding the state and structures of stock market across general elections is important for local and institutional investors in forming diversified strategies and estimating stock market stability for policy makers.

The rest of this paper is organized as follows. In Section 2, we describe the data, the MST methodology, and network topology centrality measures. In Section 3, we present and discuss the results. Finally, Section 4 presents our concluding remarks.

\section{Data and methodology \\ Data}

We use cross-correlations in the daily closing prices of 82 major stocks listed on the Pakistan stock exchange (PSX) for the blue chip companies' index, which is also known as the Karachi stock exchange (KSE-100) index, before and after three general elections in Pakistan to determine MST maps. The division of the data around the three general elections is shown in Table 1.

To study the role of every stock and the topological evolution, we construct six MSTs for before and after the general elections, where each sub-sample comprises 40 trading days. Additionally, companies are divided based on their economic activities for sectorial analysis. All 82 companies (acting as nodes in the network), individual sectors, and color for identification in the MST network are presented in Table 2. The data are obtained from the websites of (OpendoorsPK 2018), and (BusinessRecorder 2018). 
Table 1 General elections dates and sub-sample division of the Pakistan stock market

\begin{tabular}{lllll}
\hline Event & Election date & Before election & After election & $\begin{array}{l}\text { Trading } \\
\text { days }\end{array}$ \\
\hline 1 & July 25, 2018 & May 25, 2018 to July 24, 2018 & $\begin{array}{l}\text { July 26, 2018 to September 27, } \\
2018\end{array}$ & 40 \\
& May 11, 2013 & March 15, 2013 to May 10, 2013 & May 13, 2013 to July 05, 2013 & 40 \\
2 & February 18, & $\begin{array}{l}\text { December 14, 2007 to February 15, } \\
\text { 2008 }\end{array}$ & $\begin{array}{l}\text { February 19, 2008 to April 15, } \\
\text { 2008 }\end{array}$ & 40 \\
\hline
\end{tabular}

Methodology

Let $P_{i}(t)$ be the closing price of stock $i$ at time $t$, while logarithm return $r_{i}(t)$ of a stock is defined as:

$$
r_{i}(t)=\ln \left(P_{i}(t)\right)-\ln \left(P_{i}(t-1)\right)
$$

We construct correlation matrix $C=\left(c_{i j}\right)$ of size $N \times N$ among stocks $i$ and $j$ as follows:

$$
C_{i j}=\frac{\left\langle r_{i} r_{j}\right\rangle-\left\langle r_{i}\right\rangle\left\langle r_{j}\right\rangle}{\sqrt{\left(\left\langle r_{i}^{2}\right\rangle-\left\langle r_{i}\right\rangle^{2}\right)\left(\left\langle r_{j}^{2}\right\rangle-\left\langle r_{j}\right\rangle^{2}\right)}}
$$

where $r_{i}$ and $r_{j}$ are the logarithm returns of stocks $i$ and $j$, respectively, and $\langle\ldots\rangle$ is the statistical average for the period under investigation. Following the methodology of (Mantegna 1999), the correlation matrix of $(82 \times 82)$ is transformed into a distance matrix among each pair of stocks $i$ and $j$, being given by:

$$
d_{i j}=\sqrt{2\left(1-C_{i j}\right)} \text {. }
$$

The MST is a backbone network of correlation tree that uses $N-1$ linkages from $N(N-1) / 2$ cross-correlation coefficients by minimizing the sum of all edges. The 82 stocks on PSX are the nodes in the network joined by edges and characterized by weights $W$. We apply (Kruskal 1956) algorithm to an undirected graph $(G)$ of form $G=(N, E, W)$ into the MST.

To monitor the sectorial properties of Pakistan's stock market network, we examine three centrality measures-degree, closeness, and betweenness centrality-in the periods before and after the general elections. The degree of centrality of stock $i$ is given by:

$$
C_{D}(i)=\frac{\sum_{j=1}^{N} A_{i j}}{N-1},
$$

where $A_{i j}$ is the component in the $i$-th row and $j$-th column of adjacency matrix $A$. The higher the value of $C_{D}(i)$ is, the more power stock $i$ carries in influencing other stocks in the network (Marsden 2015).

Closeness centrality (Sabidussi 1966) is utilized to examine the amount of influence attached to an individual node in a network. This measure aims to examine the closeness of nodes with other nodes or sectors in the network and is defined as: 
Table 2 The 82 stocks in the KSE-100 index. Company names are in chronological order

\begin{tabular}{|c|c|c|c|c|}
\hline ID & Node & Company Name & Sector & Color \\
\hline 1 & $A B L$ & Allied Bank Limited & Commercial Banks & Blue \\
\hline 2 & ABOT & Abbot Laboratories (Pakistan) Limited & Pharmaceuticals & Khaki \\
\hline 3 & ACPL & Attock Cement (Pakistan) Limited & Cement & Red \\
\hline 4 & $\mathrm{AlCL}$ & Adamjee Insurance Company Limited & Insurance & Cream \\
\hline 5 & AKBL & Askari Bank Limited & Commercial Banks & Blue \\
\hline 6 & APL & Attock Petroleum Limited & Oil \& Gas Marketing Companies & Yellow \\
\hline 7 & ARM & Allied Rental Modarba & Modarabas & Coral \\
\hline 8 & ATLH & Atlas Honda Limited & Automobile Assembler & Cyan \\
\hline 9 & ATRL & Attock Refinery Limited & Refinery & Charcoal \\
\hline 10 & BAFL & Bank Al-Falah Limited & Commercial Banks & Blue \\
\hline 11 & BAHL & Bank Al-Habib Limited & Commercial Banks & Blue \\
\hline 12 & BATA & Bata Pakistan Limited & Leather \& Tanneries & Olive \\
\hline 13 & BNWM & Bannu Woollen Mills Limited & Woolen Products & Green \\
\hline 14 & BOP & Bank of Punjab Limited & Commercial Banks & Blue \\
\hline 15 & BWCL & Bestway Cement Limited & Cement & Red \\
\hline 16 & BYCO & Byco Petroleum Pakistan Limited & Refinery & Charcoal \\
\hline 17 & $\mathrm{CHCC}$ & Cherat Cement Company Limited & Cement & Red \\
\hline 18 & COLG & Colgate Palmolive (Pakistan) Limited & Chemical & Grey \\
\hline 19 & CPPL & Cherat Packaging Limited & Paper \& Board & Lime \\
\hline 20 & DAWH & Dawood Hercules Corporation Limited & Fertilizer & Brown \\
\hline 21 & DGKC & D.G. Khan Cement Company Limited & Cement & Red \\
\hline 22 & EFUG & EFU General Insurance Limited & Insurance & Cream \\
\hline 23 & ENGRO & Engro Corporation Limited & Fertilizer & Brown \\
\hline 24 & FABL & Faysal Bank Limited & Commercial Banks & Blue \\
\hline 25 & FCCL & Fauji Cement Company Limited & Cement & Red \\
\hline 26 & FFBL & Fauji Fertilizer Bin Qasim Limited & Fertilizer & Brown \\
\hline 27 & FFC & Fauji Fertilizer Company Limited & Fertilizer & Brown \\
\hline 28 & FML & Feroze 1888 Mills Limited & Textile Composite & Green \\
\hline 29 & GADT & Gadoon Textile Mills Limited & Textile Spinning & Green \\
\hline 30 & GATI & Gatron Industries Limited & Synthetic \& Rayon & Green \\
\hline 31 & GHGL & Ghani Glass Limited & Glass \& Ceramics & Purple \\
\hline 32 & GLAXO & GlaxoSmithKline (Pakistan) Limited & Pharmaceuticals & Khaki \\
\hline 33 & HBL & Habib Bank Limited & Commercial Banks & Blue \\
\hline 34 & HCAR & Honda Atlas Cars (Pakistan) Limited & Automobile Assembler & Cyan \\
\hline 35 & $\mathrm{HMB}$ & Habib Metropolitan Bank Limited & Commercial Banks & Blue \\
\hline 36 & HUBC & Hub Power Company Limited & Power Generation \& Distribution & Orange \\
\hline 37 & HUMNL & Hum Network Limited & Technology \& Communication & Salmon \\
\hline 38 & $\mathrm{ICl}$ & I.C.I. Pakistan Limited & Chemical & Grey \\
\hline 39 & INDU & Indus Motor Company Limited & Automobile Assembler & Cyan \\
\hline 40 & INIL & International Industries Limited & Engineering & Light Blue \\
\hline 41 & $J G I C L$ & Jubilee General Insurance Company Limited & Insurance & Cream \\
\hline 42 & $J L I C L$ & Jubilee Life Insurance Company Limited & Insurance & Cream \\
\hline 43 & KAPCO & Kot Addu Power Company Limited & Power Generation \& Distribution & Orange \\
\hline 44 & KEL & K-Electric Limited & Power Generation \& Distribution & Orange \\
\hline
\end{tabular}


Table 2 The 82 stocks in the KSE-100 index. Company names are in chronological order (Continued)

\begin{tabular}{|c|c|c|c|c|}
\hline ID & Node & Company Name & Sector & Color \\
\hline 45 & $\mathrm{KOHC}$ & Kohat Cement Limited & Cement & Red \\
\hline 46 & KTML & Kohinoor Textile Mills Limited & Textile Composite & Green \\
\hline 47 & LUCK & Lucky Cement Limited & Cement & Red \\
\hline 48 & MARI & Mari Petroleum Company Limited & Oil \& Gas Exploration Companies & Yellow \\
\hline 49 & MCB & MCB Bank Limited & Commercial Banks & Blue \\
\hline 50 & MEBL & Meezan Bank Limited & Commercial Banks & Blue \\
\hline 51 & MLCF & Maple Leaf Cement Factory Limited & Cement & Red \\
\hline 52 & MTL & Millat Tractors Limited & Automobile Assembler & Cyan \\
\hline 53 & MUREB & Murree Brewery Company Limited & Food \& Personal Care Products & Magenta \\
\hline 54 & NATF & National Foods Limited & Food \& Personal Care Products & Magenta \\
\hline 55 & NBP & National Bank of Pakistan & Commercial Banks & Blue \\
\hline 56 & $\mathrm{NCL}$ & Nishat Chunian Limited & Textile Composite & Green \\
\hline 57 & NESTLE & Nestle Pakistan Limited & Food \& Personal Care Products & Magenta \\
\hline 58 & NML & Nishat Mills Limited & Textile Composite & Green \\
\hline 59 & $N R L$ & National Refinery Limited & Refinery & Charcoal \\
\hline 60 & OGDC & Oil and Gas Development Company Limited & Oil \& Gas Exploration Companies & Yellow \\
\hline 61 & OLPL & Orix Leasing Pakistan Limited & Leasing Companies & Navy \\
\hline 62 & PAKT & Pakistan Tobacco Company Limited & Tobacco & Chocolate \\
\hline 63 & $\mathrm{PICT}$ & Pakistan International Container Terminal Limited & Transport & Black \\
\hline 64 & $\mathrm{PIOC}$ & Pioneer Cement Limited & Cement & Red \\
\hline 65 & PKGS & Packages Limited & Paper \& Board & Lime \\
\hline 66 & PMPK & Philip Morris (Pakistan) Limited & Tobacco & Chocolate \\
\hline 67 & POML & Punjab Oil Mills Limited & Vanaspati \& Allied Industries & Maroon \\
\hline 68 & PPL & Pakistan Petroleum Limited & Oil \& Gas Exploration Companies & Yellow \\
\hline 69 & PSMC & Pak Suzuki Motor Company Limited & Automobile Assembler & Cyan \\
\hline 70 & PSO & Pakistan State Oil Company Limited & Oil \& Gas Marketing Companies & Yellow \\
\hline 71 & PTC & Pakistan Telecommunication Company Limited & Technology \& Communication & Salmon \\
\hline 72 & SCBPL & Standard Chartered Bank Limited & Commercial Banks & Blue \\
\hline 73 & SEARL & The Searle Company Limited & Pharmaceuticals & Khaki \\
\hline 74 & SHEL & Shell Pakistan Limited & Oil \& Gas Marketing Companies & Yellow \\
\hline 75 & SHFA & Shifa International Hospitals Limited & Miscellaneous & Silver \\
\hline 76 & SML & Shakarganj Limited & Sugar \& Allied Industries & Teal \\
\hline 77 & SNBL & Soneri Bank Limited & Commercial Banks & Blue \\
\hline 78 & SNGP & Sui Northern Gas Pipelines Limited & Oil \& Gas Marketing Companies & Yellow \\
\hline 79 & SSGC & Sui Southern Gas Company Limited & Oil \& Gas Marketing Companies & Yellow \\
\hline 80 & THALL & Thal Limited & Automobile Parts \& Accessories & Cyan \\
\hline 81 & TRG & TRG Pakistan Limited & Technology \& Communication & Salmon \\
\hline 82 & UBL & United Bank Limited & Commercial Banks & Blue \\
\hline
\end{tabular}




$$
\operatorname{Cc}(k)=\frac{1}{\sum_{h \in G} d_{G}(k, h)},
$$

where $d_{G}(k, h)$ represents the minimum distance between nodes $k$ and $h$. Finally, to analyze the intermediary role of a node in the network, betweenness centrality is used to evaluate the frequency of a node acting as shortest link among two nodes and in transferring valuable information to the network:

$$
C_{B}(k)=\sum_{s \neq k \neq t \in V} \frac{\sigma_{s t}(k)}{\sigma_{s t}},
$$

where $\sigma_{s t}$ is the number of shortest paths between nodes $s$ and $t$.

\section{Results and discussion}

Here, we present six MSTs of 82 stocks in KSE-100 of Pakistan stock market before and after three general elections (2018, 2013, and 2008). The stocks (nodes) are colored based on their business sectors, as per Table 2 .

Figure 1 shows the MST map before the general election of 2018. There is no single most dominant stock, but four principal nodes ${ }^{1}$ : Nishat Mills (NML 6), D.G. Khan Cement (DGKC 5), Kohat Cement (KOHC 5), and Sui Northern Gas (SNGP 5). Therefore, MST highlights the strong dependency of Pakistan's economy on cement, textile, and oil and gas sectors before the 2018 election. Additionally, the results show that the stocks in the cement (red) and oil and gas (yellow) sectors form clusters and connect with each other. However, companies in the commercial banks sector (blue) are split into two groups, one at the bottom left of the map and one on the middle-right side. Furthermore, a strong intermediary role is being played by SNGP, which is carrying the highest betweenness centrality score of 2265 .

The MST map after election 2018 of the KSE-100 index companies is presented in Fig. 2. We observe the scattered pattern of the commercial banking sector, where banks are linked to companies from other sectors. Similarly, oil and gas companies are separated from one major cluster before elections 2018 to a disbursed distribution after elections period. The split of these two sectors possibly reflect different responses to the risks constituted by general elections. In terms of connectivity, a main hub node is Lucky Cement (LUCK 10), followed by three key nodes: D.G. Khan Cement (DGKC 7), ENGRO Corporation (ENGRO 5), and Kohat Cement (KOHC 5). Several emerging countries such as South Africa (Majapa and Gossel 2016), Brazil (Tabak et al. 2010), China (Zhuang et al. 2008), and India (Sinha and Pan 2007) have key nodes in the MST, which is not uncommon on Pakistan's stock market. In sum, the MST shows a star-like structure after the general elections of 2018, possibly reflecting a structural transition.

Figure 3 represents the 2013 pre-election MST map of the KSE-100 network. The figure shows a tree-like structure of the MST (Nobi et al. 2015) due to low value of centrality. The three key nodes of Mapple Leaf Cement (MLCF), Pak Suzuki Motors (PSMC), and Searle Company (SEARL) have a maximum of five connections each in the 2013 pre-election period. In addition, there is no major cluster formation and reduced connectivity in the network. Only three cement sector companies-DGKC,

\footnotetext{
${ }^{1}$ The number against each stock symbol specifies the number of connections per node.
} 


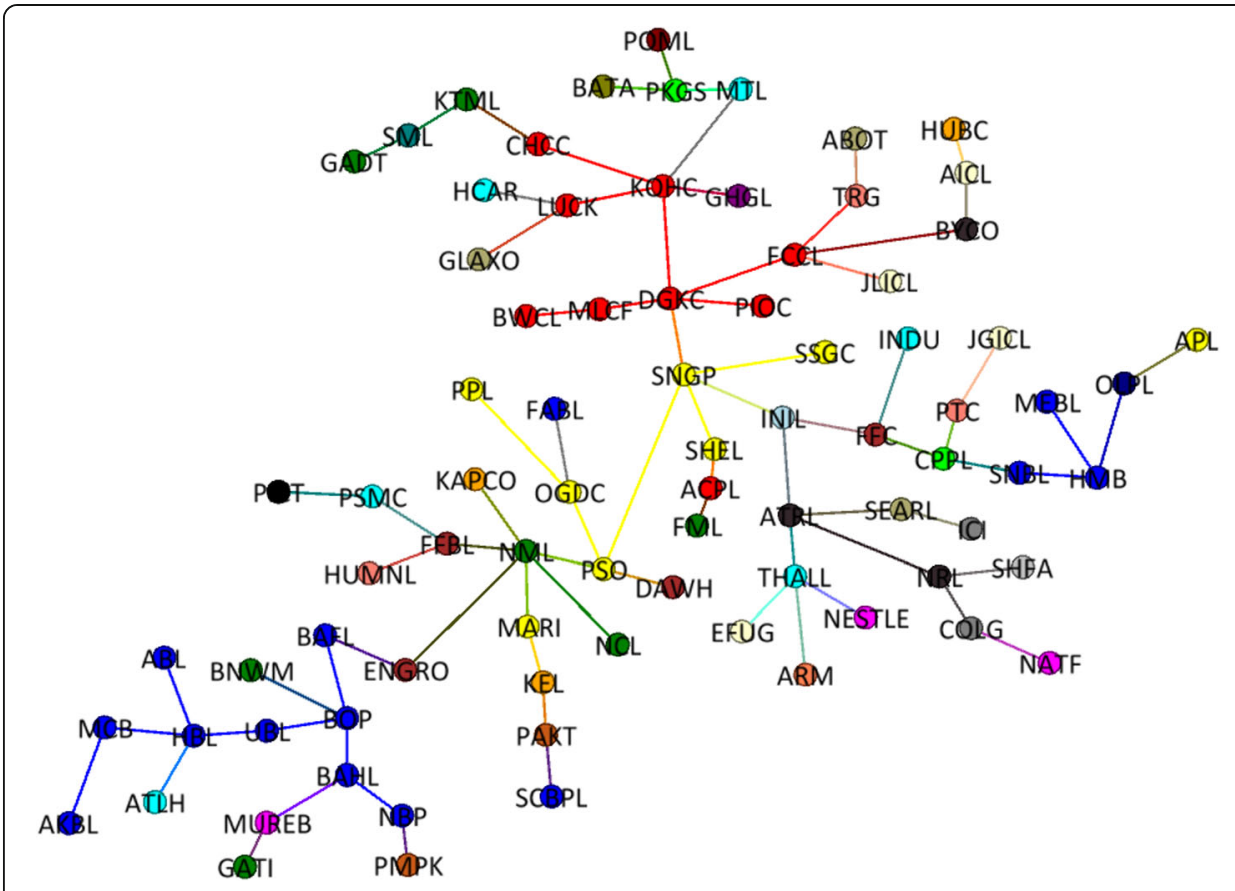

Fig. 1 MST map before the 2018 elections for the 82 stocks in KSE-100

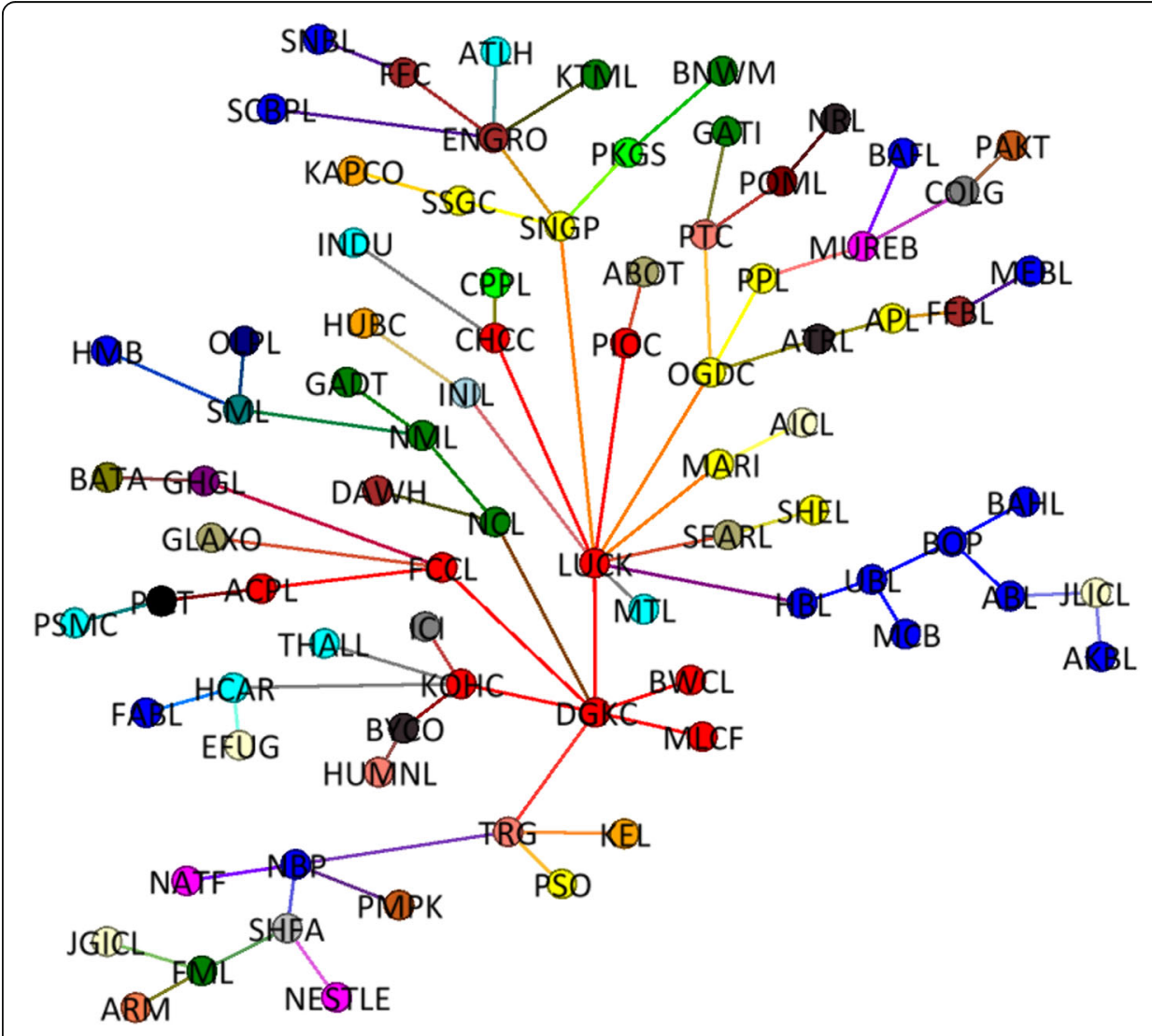

Fig. 2 MST map after the 2018 elections of 82 stocks in KSE-100 


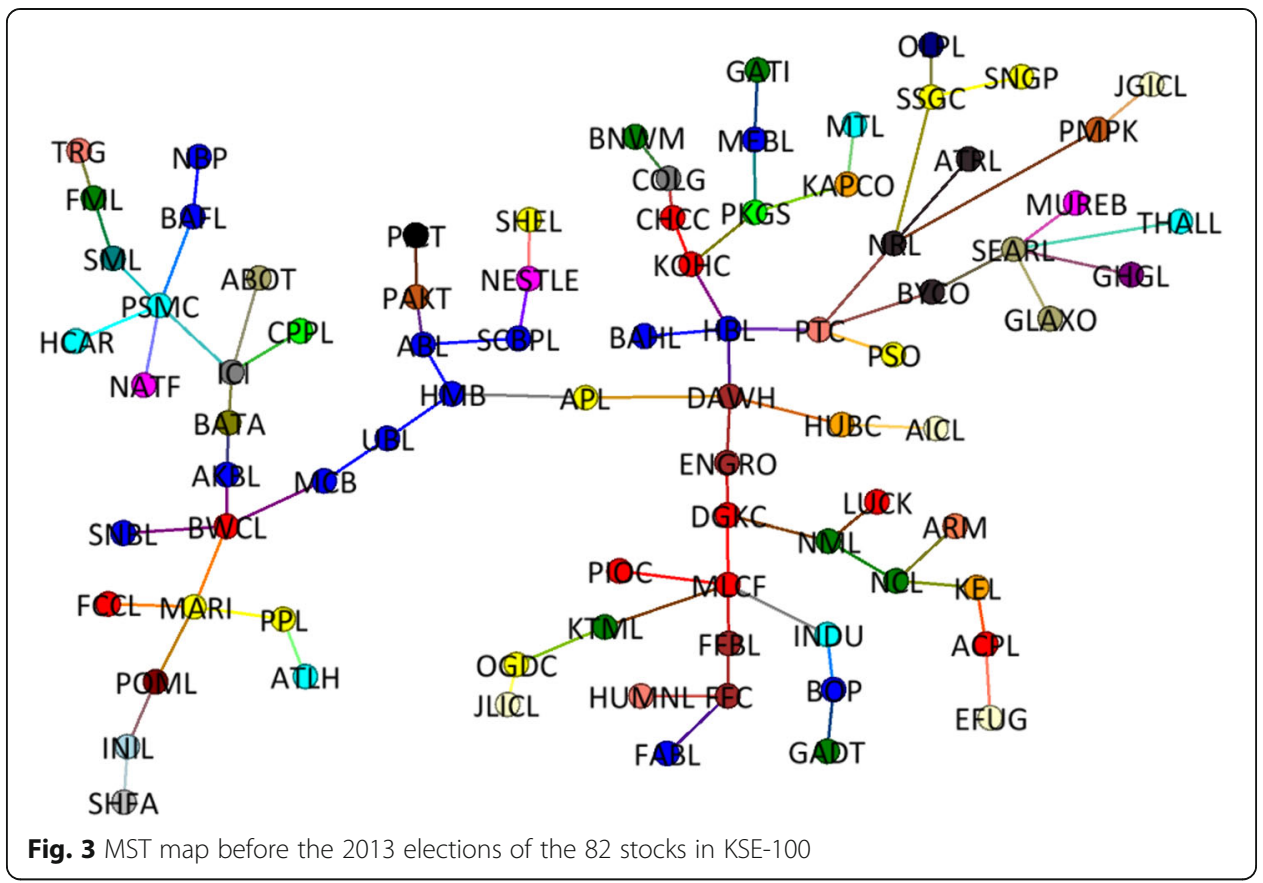

MLCF, and PIOC - connect with each other, the rest linking with companies from different sectors. Further, companies from almost all the sectors are scattered, and around $77 \%$ of nodes have two or fewer connections.

The MST map of the KSE-100 index after the general elections of 2013 is presented in Fig. 4. We can observe a slight increase in the degree of connectivity per node for Maple Leaf Cement (MLCF 6), while four nodes-Cherat Packaging (CPPL), Hub Power (HUBC), Kohinoor Textile Mills (KTML), and Nishat Mills (NML)-have five connections each. Additionally, Searle (SEARL) and Pak Suzuki (PSMC) nodes have now two and one

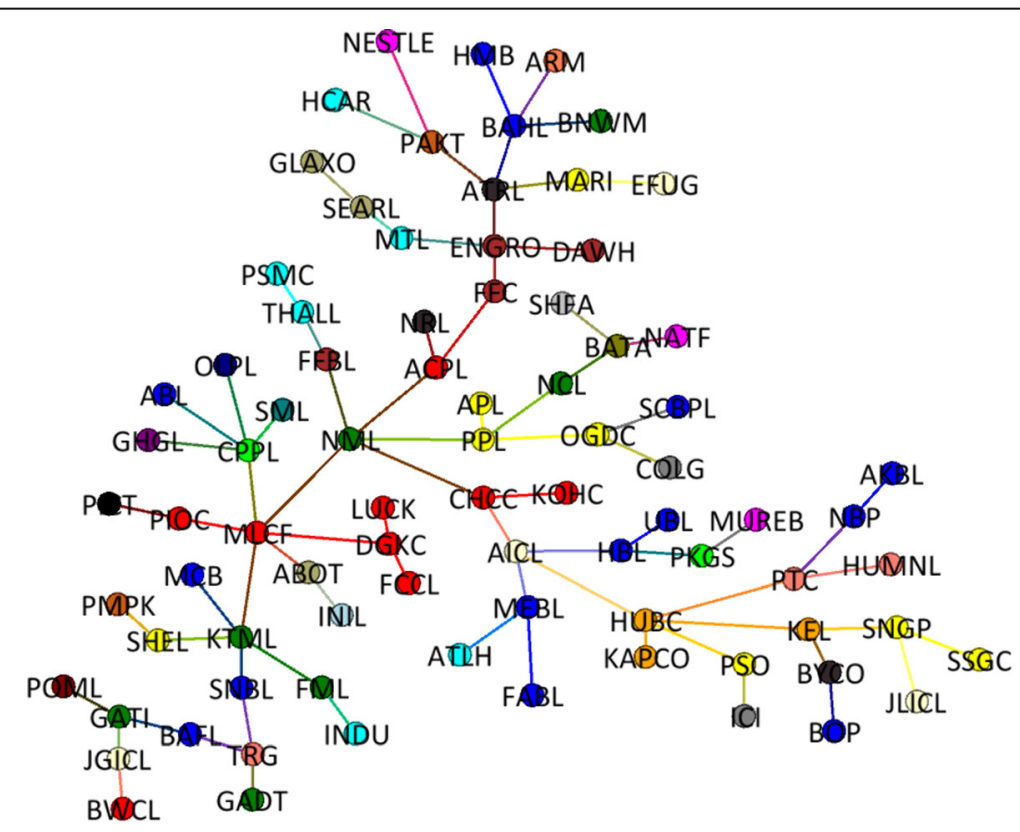

Fig. 4 MST map after the 2013 elections of the 82 stocks in KSE-100 
connection, respectively. This reconfiguration possibly represents the diversification of these companies after the general elections. The MST in post the 2013 election has a tree-like structure compared to the star-like structure in the post 2018 election period.

The pre-2008 election MST map of the KSE-100 index companies is presented in Fig. 5. A major node is Pakistan Petroleum (PPL 9), followed by two significant nodes-Nishat Mills (NML 7) and Muslim Commercial Bank (MCB 5). Hence, PPL is the dominating company in the network before the 2008 general elections, and companies surrounding this node will be directly influenced by any shock due to the general elections (Sharif et al. 2016). Additionally, the oil and gas sector (yellow) and commercial banking sector (blue) cluster, whereas cement sector nodes (FCCL, MLCF, CHCC, PIOC, ACPL, LUCK) are spread over the entire network.

Figure 6 shows the post 2008 election MST map of KSE-100 index network. We observe a tree-like structure and reduction in the degree of connections per node compared to the star-like structure before the election. D.G. Khan Cement (DGKC 7) is the most significant and central node, followed by Attock Refinery (ATRL 6) and Oil and Gas Development Company (OGDC 5). However, PPL has moved from nine connections before election to three. Additionally, companies from the cement sector form a cluster. Overall, the results show a structural change in the network topology from before to after the 2008 general elections.

\section{Sectorial centrality measures}

We here present the sectorial centrality properties of the KSE-100 index MST network for all three general elections. As centrality measures are important in network analysis

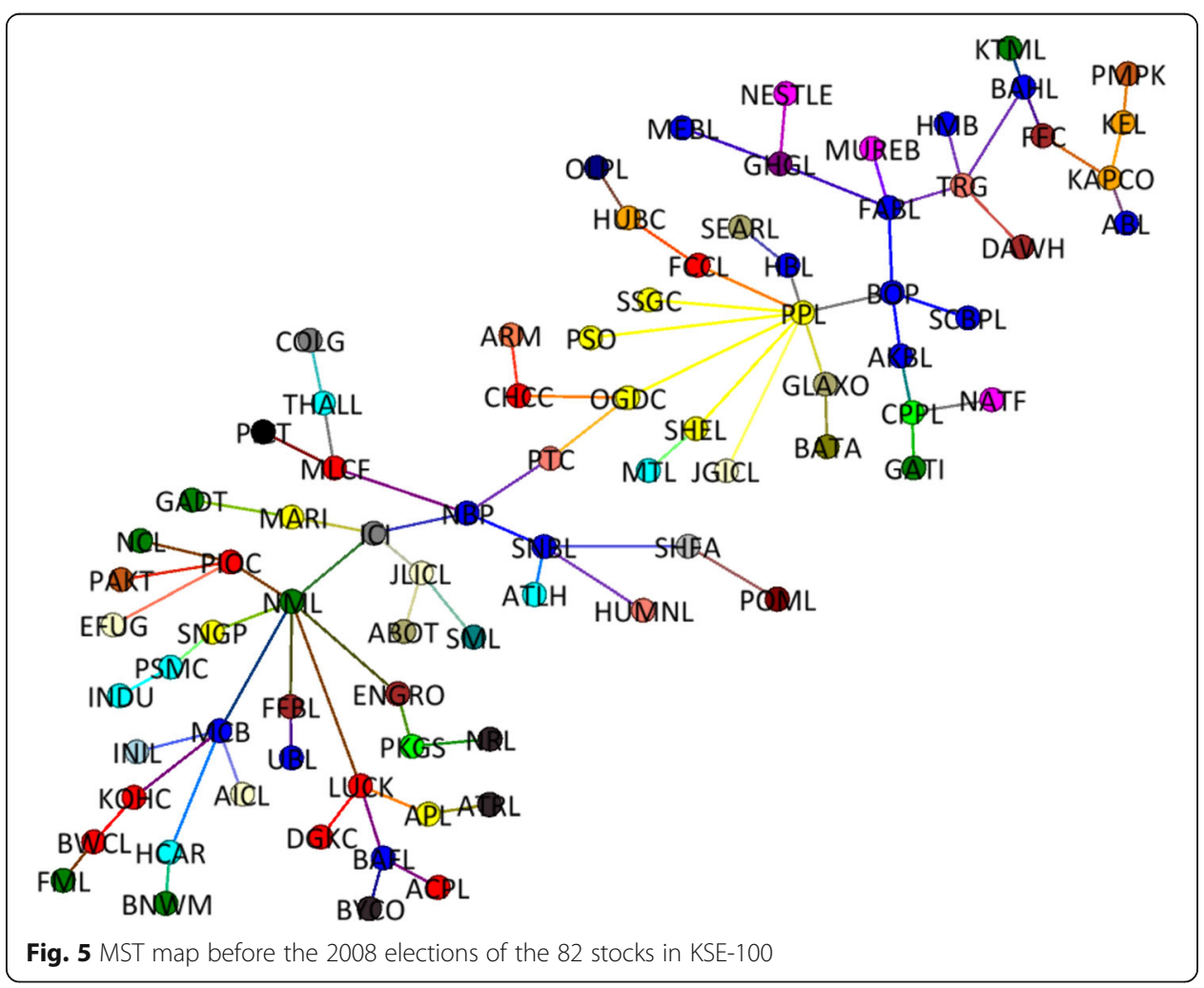




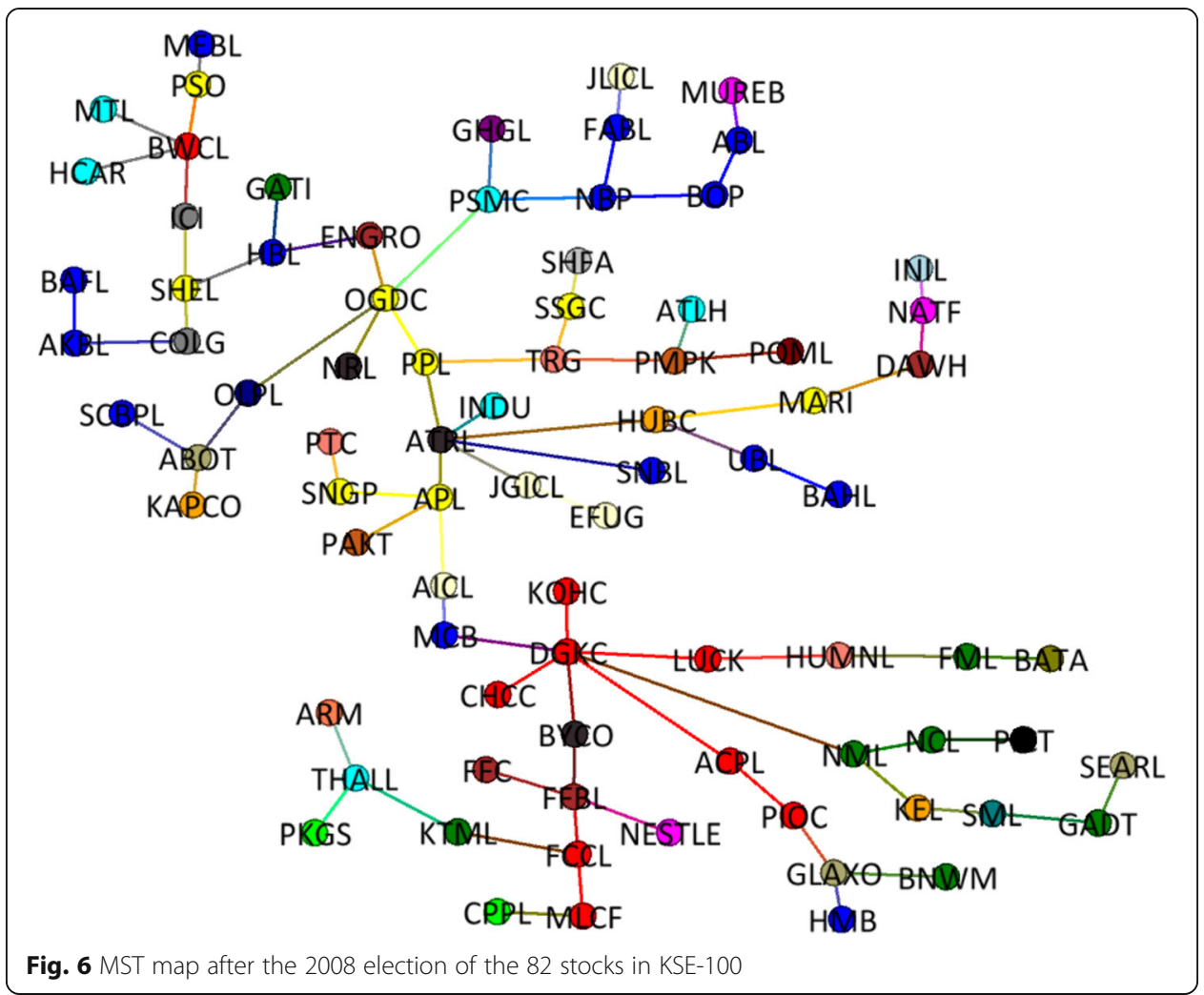

to examine the behavior of networks (Ghanbari et al. 2018), we present the average sectorial degree of centrality in Fig. 7. The figure shows the cement sector nodes have a mean of approximately three incident edges, followed closely by oil and gas and fertilizer sectors with means of two and half. We can observe a large increase in the average number of incident edges for the nodes in the cement sector after the 2018 general elections compared to any other sectors. The other sector that exhibits an increase in connectivity is the paper and board sector after the 2013 elections. This increase in the number of edges highlights an expansion in the economic activities of these sectors in the elections periods. Additionally, the results show a consistent decrease in the connectivity of commercial banks in all the three post-election periods, compared to the high average degree of connections during the pre-elections periods. The comparison between pre- and post-elections centrality metrics shows a consistent average connectivity in the textile sector during all periods, except for a substantial increase in the post 2013 election period.

Figure 8 presents the average sectorial closeness centrality for the periods before and after the elections. The cement sector has a large average closeness centrality of 0.26 after the 2018 election, followed by the oil and gas (0.22), pharmaceutical (0.22), technology and communications $(0.21)$, and paper and board 0.21 sectors over the same period. This could be interpreted as the key role of these sectors in the MST after the 2018 election. Additionally, the cement sector is closer to other sectors' nodes as the companies from this sector have the highest average closeness centrality. By contrast, the lowest average closeness centrality is registered by the paper and board sector ( 0.090 after the 2008 general elections. However, the overall average closeness centrality is 0.15 for all sectors during all periods. 


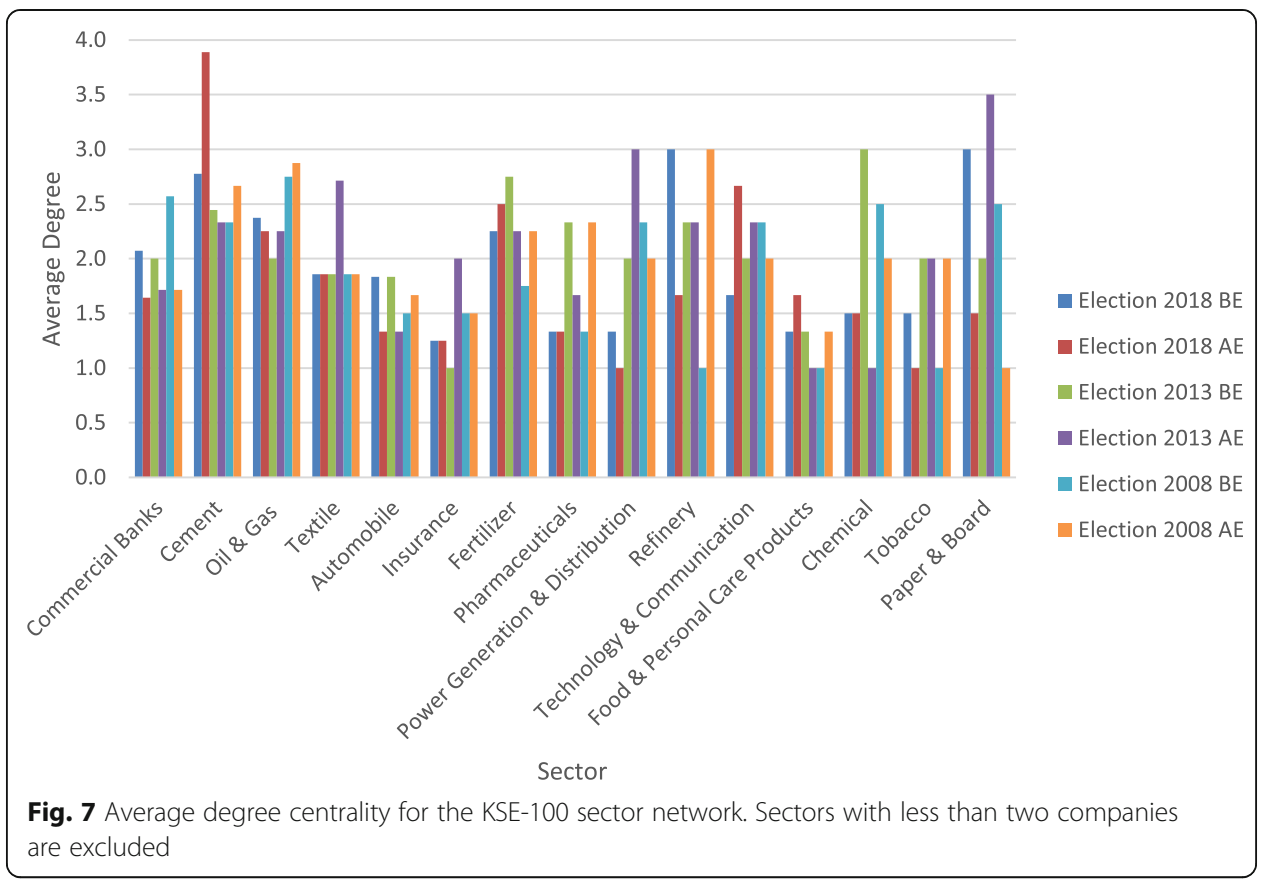

Regarding average sectorial betweenness centrality, Fig. 9 shows that the fertilizer sector has the maximum number of shortest routes and has a strong mediating role, especially before the 2013 elections. Additionally, the average betweenness centralities of the oil and gas and cement sectors are also high. Similarly, an increase in the mediation effect of the cement sector is also registered after the 2018 election. Furthermore, the food and personal care products, tobacco, pharmacy, and automobile sectors present the lowest overall average betweenness centrality scores, reflecting their weak mediation effects.

\section{Conclusions}

We presented the topology of the network formed by the 82 main stocks on the Pakistan stock market using MST for the three general elections in 2018, 2013, and 2008. We observed the status of and changes in the MST network as a result of these political events. The MST had no dominant node, but had two major clusters for the cement and oil and gas sectors and a tree-like structure before the general elections of 2018, compared to a star-like structure and a major node (LUCK) and broken clusters after the 2018 elections. Comparatively, for the 2013 elections, we found a decrease in the connectivity and scattered sectors before the elections and an improvement in connectivity due to diversification after the elections. A star-like structure of the MST is observed before the 2008 elections, with the dominating node being PPL compared to a significant drop in connections and in PPL's influence along with a tree-like structure after the 2008 general elections. In addition to the six MST maps, we also assessed our results by using degree centrality, sectorial closeness, and betweenness centrality. The average sectorial degree of centrality measure shows the economic expansion and highest number of incident edges for the cement sector nodes, followed by the oil and gas and fertilizer sectors. Similarly, the sectorial closeness and betweenness centrality 


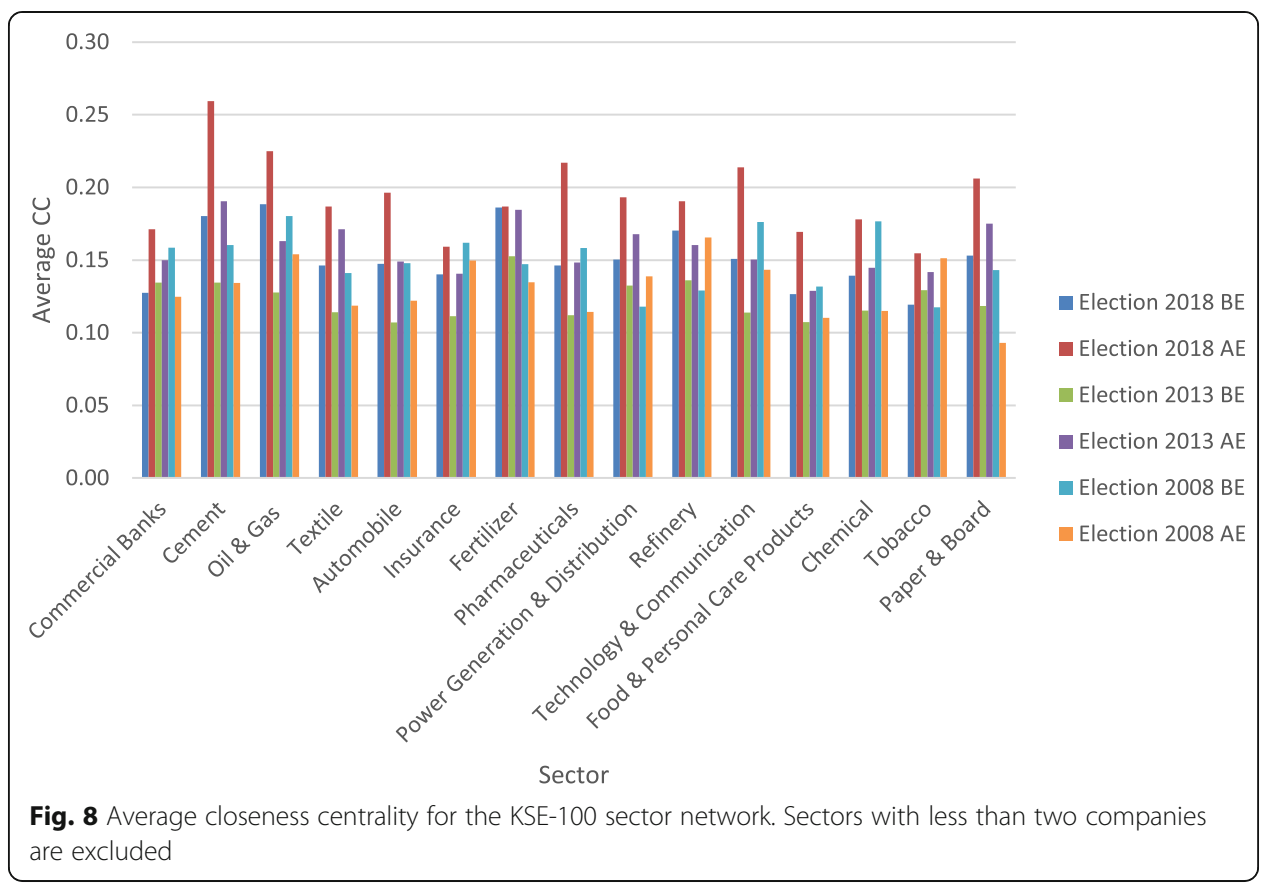

measures revealed the importance of the cement sector nodes and strong overall intermediary role of the fertilizer sector.

Studying stock market topology around general elections has significant implications for local and international investors for portfolio management, such as forming optimal diversification strategies. Additionally, identification of core nodes and sectors, systematic and political risk assessment is useful for policy makers or regulators in assuring stock market stability. Our study examines stock market structural change and

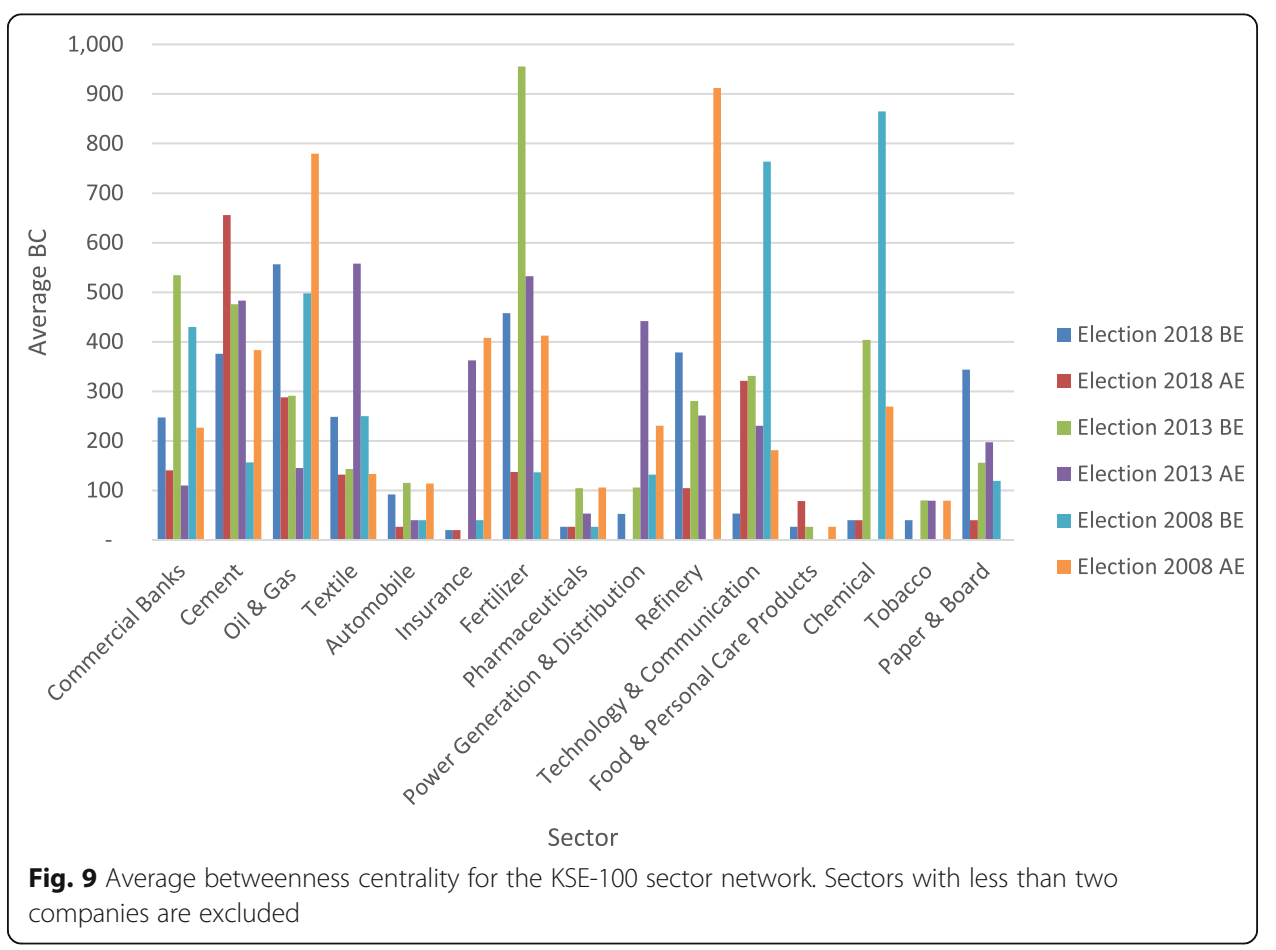


topological evolution around general elections through MST technique. Perhaps, we could compare networks formed through alternative methods of PMFG (Tumminello et al. 2005), and asset graphs (Onnela et al. 2003b, c). In addition, we can analyze the impact of various political and macroeconomic events on rolling windows of different sizes in a temporary dynamic stock market network. Further, we can apply MST method to analyze structural change and dynamics around political event of general elections into other stock markets (e.g., developed markets or other emerging markets). The future research may address these limitations.

\section{Abbreviations}

AR: Abnormal returns; CAAR: Cumulative average abnormal returns; KSE: Karachi Stock Exchange; MST: Minimum Spanning Tree; PMFG: Planar maximally filtered graph; PSX: Pakistan Stock Exchange

\section{Acknowledgements}

We are grateful to the editor and anonymous referees for their insightful suggestions. We also thank the Southwestern University of Finance and Economics for providing open access to our article.

\section{Authors' contributions}

BAM (First \& Corresponding Author) carried out the idea, designed the research, analyzed and interpreted data, applied methodology and visualization, discussed the results and wrote the article. HY (second author) supervised the research, provided necessary resources, and reviewed the article. RT (third author) helped in data collection, and revising the article. All authors read and approved the final manuscript.

\section{Funding}

Not applicable.

\section{Availability of data and materials}

Data are available on http://www.opendoors.pk/ and https://markets.brecorder.com/.

\section{Competing interests}

The authors declare that they have no competing interests.

\section{Author details}

${ }^{1}$ School of Finance and Economics, Jiangsu University, 01 Xuefu Road, Zhenjiang 212013, Jiangsu, China. ${ }^{2}$ School of Computer Science, Jiangsu university, Zhenjiang 212013, China.

Received: 25 February 2019 Accepted: 26 November 2019

Published online: 07 January 2020

\section{References}

Abidin SZ, Old C, Martin T (2010) Effects of New Zealand general elections on stock market returns. Int Rev Bus Res Papers 6: $1-12$

Białkowski J, Gottschalk K, Wisniewski TP (2008) Stock market volatility around national elections. J Bank Financ 32:1941-1953 Boginski V, Butenko S, Pardalos PM (2005) Statistical analysis of financial networks. Comput Stat Data Anal 48:431-443 BusinessRecorder (2018). Available: https://markets.brecorder.com/ [Accessed 06 Jan 2019]

Chiu D, Ying M, Yu P (2012) A study of Taiwan political elections and stock market dynamism. 2012 Sixth International Conference on Genetic and Evolutionary Computing, 25-28 Aug 2012. 562-565

Coletti P, Murgia M (2016) The network of the Italian stock market during the 2008-2011 financial crises. Algorithmic Finance 5:111-137

Dias J (2012) Sovereign debt crisis in the European Union: a minimum spanning tree approach. Phys A Stat Mech Appl 391 : 2046-2055

Ghanbari R, Jalili M, Yu X (2018) Correlation of cascade failures and centrality measures in complex networks. Futur Gener Comput Syst 83:390-400

Goodell JW, Mcgroarty F, Urquhart A (2015) Political uncertainty and the 2012 US presidential election: A cointegration study of prediction markets, polls and a stand-out expert. Int Rev Financ Anal 42:162-171

Jang W, Lee J, Chang W (2011) Currency crises and the evolution of foreign exchange market: evidence from minimum spanning tree. Phys A Stat Mech Appl 390:707-718

Kou G, Chao X, Peng Y, Alsaadi FE, Herrera-Viedma E (2019) Machine learning methods for systemic risk analysis in financial sectors. Technol Econ Dev Econ 25:716-742

Kou G, Peng Y, Wang G (2014) Evaluation of clustering algorithms for financial risk analysis using MCDM methods. Inf Sci 275: $1-12$

Kruskal JB (1956) On the shortest spanning subtree of a graph and the traveling salesman problem. Proc Am Math Soc 7(1): 48-50

Lee JW, Nobi A (2018) State and network structures of stock markets around the global financial crisis. Comput Econ 51:195210

Liew VK-S, Rowland R (2016) The effect of Malaysia general election on stock market returns. SpringerPlus 5:1975 
Majapa M, Gossel SJ (2016) Topology of the south African stock market network across the 2008 financial crisis. Phys A Stat Mech Appl 445:35-47

Mantegna RN (1999) Hierarchical structure in financial markets. Eur Phys J B 11(1):193-197

Marsden PV (2015) Network centrality, measures of. In: Wright JD (ed) International encyclopedia of the Social \& Behavioral Sciences (second edition). Elsevier, Oxford

Memon BA, Yao H (2019) Structural change and dynamics of Pakistan stock market during crisis: A complex network perspective. Entropy 21:248

Musmeci N, Aste T, di Matteo T (2016) Interplay between past market correlation structure changes and future volatility outbursts. Sci Rep 6:36320

Nobi A, Maeng SE, Ha GG, Lee JW (2015) Structural changes in the minimal spanning tree and the hierarchical network in the Korean stock market around the global financial crisis. J Korean Phys Soc 66:1153-1159

Oehler A, Walker TJ, Wendt S (2013) Effects of election results on stock price performance: evidence from 1980 to 2008. Manag Financ 39:714-736

Onnela JP, Chakraborti A, Kaski K, Kertész J (2003a) Dynamic asset trees and black Monday. Phys A Stat Mech Appl 324:247252

Onnela JP, Chakraborti A, Kaski K, Kertész J, Kanto A (2003b) Dynamics of market correlations: taxonomy and portfolio analysis. Phys Rev E 68:056110

Onnela JP, Chakraborti A, Kaski K, Kertsz J, Kanto A (2003c) Asset trees and asset graphs in financial markets. Phys Scr T106:48

OpendoorsPK (2018) Available: http://www.opendoors.pk/ [Accessed 04 Jan 2019]

Pantzalis C, Stangeland DA, Turtle HJ (2000) Political elections and the resolution of uncertainty: the international evidence. J Bank Financ 24:1575-1604

Pástor L', Veronesi P (2013) Political uncertainty and risk premia. J Financ Econ 110:520-545

Radhakrishnan S, Duvvuru A, Sultornsanee S, Kamarthi S (2016) Phase synchronization based minimum spanning trees for analysis of financial time series with nonlinear correlations. Phys A Stat Mech Appl 444:259-270

Sabidussi G (1966) The centrality index of a graph. Psychometrika 31:581-603

Savita, Ramesh A (2015) Return volatility around National Elections: evidence from India. Procedia Soc Behav Sci 189:163-168

Sharif S, Ismail S, Zurni O, Theng LH (2016) Validation of global financial crisis on Bursa Malaysia stocks market companies via covariance structure. Am J Appl Sci 13:1091-1095

Sinha S, Pan RK (2007) Uncovering the internal structure of the Indian financial market: large cross-correlation behavior in the NSE. In: Chatterjee A, Chakrabarti BK (eds) Econophysics of markets and business networks: proceedings of the Econophys-Kolkata III. Springer Milan, Milano

Sultonov M, Jehan SN (2018) Dynamic linkages between Japan's foreign exchange and stock markets: response to the Brexit referendum and the 2016 U.S. Presidential election. J Risk Financ Manage 11:34

Sultornsanee S, Duvvuru A, Radhakrishnan S, Chowdhary H, Kamarthi S (2013) Phase synchronization based minimum spanning trees for the analysis and visualization of currency exchange markets. Proc Comput Sci 20:460-465

Tabak BM, Serra TR, Cajueiro DO (2010) Topological properties of stock market networks: the case of Brazil. Phys A Stat Mech Appl 389:3240-3249

Tumminello M, Aste T, di Matteo T, Mantegna RN (2005) A tool for filtering information in complex systems. Proc Natl Acad Sci 102:10421-10426

Wang G-J, Xie C, Chen S (2017) Multiscale correlation networks analysis of the US stock market: a wavelet analysis. J Econ Interac Coord 12:561-594

Wiliński M, Sienkiewicz A, Gubiec T, Kutner R, Struzik ZR (2013) Structural and topological phase transitions on the German stock exchange. Phys A Stat Mech Appl 392:5963-5973

Xia L, You D, Jiang X, Guo Q (2018) Comparison between global financial crisis and local stock disaster on top of Chinese stock network. Phys A Stat Mech Appl 490:222-230

Yan X-G, Xie C, Wang G-J (2015) Stock market network's topological stability: evidence from planar maximally filtered graph and minimal spanning tree. Int J Modern Phys B 29:1550161

Yang R, Li X, Zhang T (2014) Analysis of linkage effects among industry sectors in China's stock market before and after the financial crisis. Phys A Stat Mech Appl 411:12-20

Yao H, Memon BA (2019) Network topology of FTSE 100 index companies: from the perspective of Brexit. Phys A Stat Mech Appl 523:1248-1262

Zhang Y, Lee GHT, Wong JC, Kok JL, Prusty M, Cheong SA (2011) Will the US economy recover in 2010? A minimal spanning tree study. Phys A Stat Mech Appl 390:2020-2050

Zhao L, Wang G-J, Wang M, Bao W, Li W, Stanley HE (2018) Stock market as temporal network. Phys A Stat Mech Appl 506: 1104-1112

Zhuang R, Hu B, Ye Z (2008) Minimal spanning tree for Shanghai-Shenzhen 300 stock index. 2008 IEEE Congress on Evolutionary Computation (IEEE World Congress on Computational Intelligence), 1-6 June 2008. 1417-1424

\section{Publisher's Note}

Springer Nature remains neutral with regard to jurisdictional claims in published maps and institutional affiliations. 